\title{
Value-based chronic care model approach for vulnerable older patients with multiple chronic conditions
}

\author{
John F. Gibbs ${ }^{1}$, Ellen Guarnieri ${ }^{2}$, Quyen D. Chu ${ }^{3}$, Kenneth Murdoch ${ }^{4}$, Arif Asif ${ }^{5}$ \\ ${ }^{1}$ Department of Surgery, Hackensack Meridian Health School of Medicine at Seton Hall University, Nutley, NJ, USA; ${ }^{2}$ Department of Healthcare \\ Quality and Safety, Thomas Jefferson University College of Population Health, Philadelphia, PA, USA; ${ }^{3}$ Department of Surgery, LSU-Shreveport \\ School of Medicine, Shreveport, LA, USA; ${ }^{4}$ Department of Nursing, Jersey Shore University Medical Center, Neptune, NJ, USA; ${ }^{5}$ Department of \\ Medicine, Hackensack Meridian School of Medicine at Seton Hall University, Nutley, NJ, USA \\ Contributions: (I) Conception and design: All authors; (II) Administrative support: None; (III) Provision of study materials or patients: None; (IV) \\ Collection and assembly of data: JF Gibbs, E Guarnieri, K Murdoch; (V) Data analysis and interpretation: All authors; (VI) Manuscript writing: All \\ authors; (VII) Final approval of manuscript: All authors. \\ Correspondence to: John F. Gibbs, MD, MHCM. Hope Tower Oncology Administration, 19 Davis Ave., Neptune, NJ 07731, USA. \\ Email: John.Gibbs@hackensackmeridian.org.
}

\begin{abstract}
Old age, itself, is not a disease" (Suborne 2007). The rising rate of the global aging population is predicted to create a health care crisis within the next three decades. Vulnerable older adults suffer from multiple chronic conditions (MCCs) in addition to cognitive and physical decline during the process of aging resulting in an inability to optimally achieve self-management. In terms of resource utilization, complex inpatient, and outpatient care results in higher physician visits, polypharmacy, and higher prescription costs. Health literacy has become known as an important social determinant of health affecting the older population. Both reductions in health literacy and self-management are associated with poorer health outcomes. The patient activation measure (PAM) has been coined "a vital sign" to ascertain a patient activation level throughout the continuum of care with the introduction of an intervention's progress. In this review, we conceptualize a systematic approach of the development of a "tailored" integrated community and care team to develop a partnership in assisting senior adults with MCCs. Through this intervention the value-based chronic care model (CCM) and PAM allows for an adaptable integration between the activated patient, their caregivers, and the community. The Model for Improvement (MFI) serves as a well-recognized technique for developing and executing quality improvement strategies in this "tailored" engaged and activated individual and community care team approach in achieving health outcomes and quality of life among the vulnerable older adult population worldwide.
\end{abstract}

Keywords: Multiple chronic conditions (MCCs); older population; chronic care model (CCM); global; Medicare; patient activation; Model for Improvement (MFI)

Submitted Aug 08, 2020. Accepted for publication Sep 21, 2020.

doi: 10.21037/jgo-20-317

View this article at: http://dx.doi.org/10.21037/jgo-20-317

\section{Aging population worldwide with multiple chronic conditions (MCCs)}

Globally, the elderly population (greater than 65 years of age) is expected to triple to 1.5 billion by 2050 with many countries forecasted to face health care crisis levels (Figure 1) (1). In the United States (U.S.), the increasing population is creating dramatic concerns for the future care of the Medicare population. By 2030, the U.S. adult

\footnotetext{
$\wedge$ ORCID: 0000-0003-0037-8014.
} 


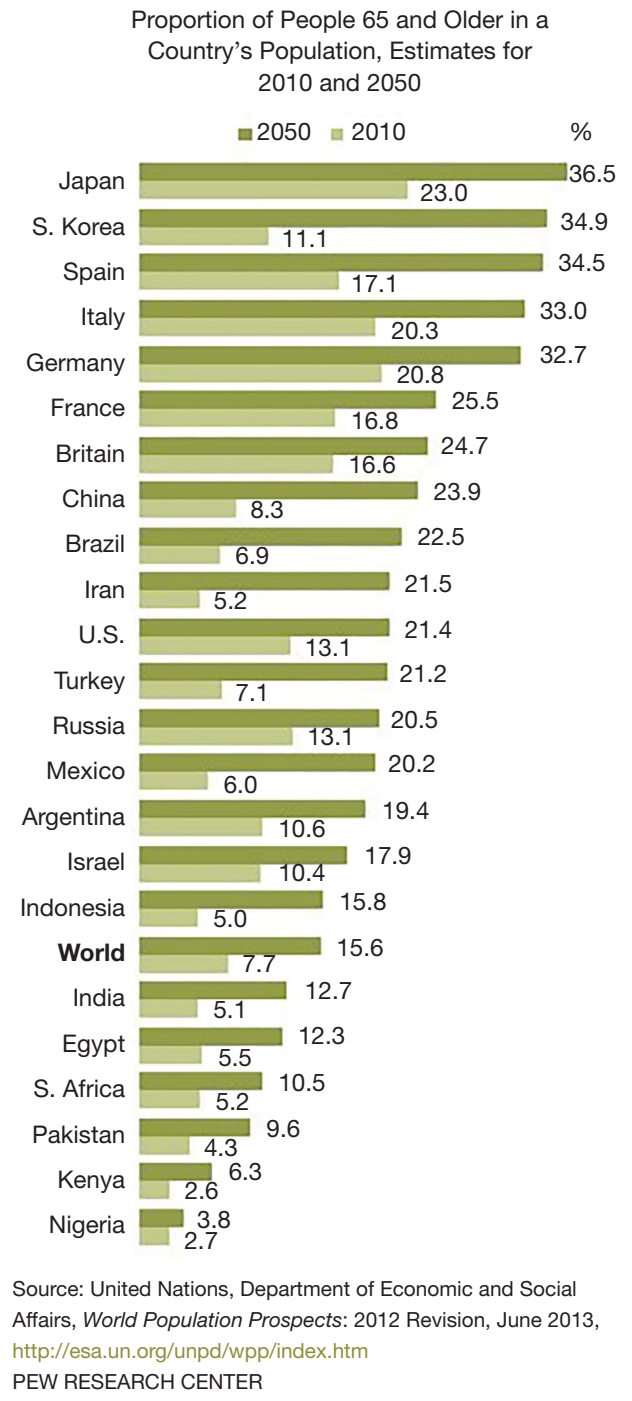

Figure 1 The projected growth of the older population, by 2050, globally is expected to significantly tax all countries health care systems in acceptable economic and financial cost control while maintaining health outcomes. With permission, Pew Research (1). https://www.pewresearch.org/.

population (65 years or order) will increase to 72.8 million double that of $2000(2,3)$. The proportion of older adults over 80 years or greater will triple by 2050 (Figure 2). With an aging global population, health care costs will comprise a larger portion of the gross domestic products among countries, especially those of low to low-to-middle countries (4). Worldwide, $60 \%$ of all deaths are attributable to the following major chronic conditions-cardiovascular disease, cancer, chronic lung diseases, and diabetes (5).
The World Health Organization (WHO) defined noncommunicable diseases (NCD) as those conditions that "tend to be of long chronic duration and are the result of a combination of genetic, physiological, environmental and behavioral factors (6)." The shift away from a perceived negative connotation of NCD and the lack of a consistent term representing chronic disease led to considerable differences in prevalence and burden estimates. (7). MCCs, defined as two or more chronic conditions, is considered unambiguous and has emerged at the preferred term across multiple geographies and languages (8). Within the older population, the accumulation of MCC is associated with increased risk of death, resource utilization, and health care cost (8). In terms of resource utilization, complex inpatient, and outpatient care results in high use of specialists, multiple primary physician visits, polypharmacy, and higher prescription costs (8). Older adults with MCCs have between two and five times the number of physician visits when compared to a comparable age group without chronic diseases. Patients with three or more MCCs utilize prescribed medications at a rate 2.1 times more than peers with a cost 6.6 times higher than peers with less than two chronic conditions. The Agency for Healthcare Research and Quality (AHRQ) funded Medical Expenditure Panel Survey depicts the association among all patients of increasing MCCs and inpatient admissions (Figure 3) (5). The study found that among all American inpatients, the number of individuals with MCC comprise $70.6 \%$ of the total. Dramatically, $38.5 \%$ of these admitted patients had five or more MCCs (5). Older adults, in the U.S., with three or more MCCs had a higher number of hospital bed days. Medicare patients with MCCs taking polypharmacy regimens are considered the highest population risk and reportedly comprise $50 \%$ of health care costs. Upon hospital admission, $82 \%$ of patients were found to have at least one medication discrepancy (9). Medication adherence rates were $79 \%$ with one dose, $69 \%$ with two doses, $65 \%$ with three doses, and $51 \%$ with four doses (10). Major predictors of poor adherence include cognitive impairment, inadequate discharge, medication side effects, complexity of treatment, and medication cost (11).

The older adult population experience a complex array of varying physical, social, and cognitive factors that may impact their ability to remain autonomous in daily life. Multiple descriptions defining the aging process and vulnerability have been offered. De Groot et al. (2019) defined "vulnerability as a dynamic state that reflects converging effects of a set of interacting and amplifying personal and environmental factors, which together increase an individual's 


\section{The U.S. population ages 80 and older will nearly triple between 2010 and 2050; the number of people ages 90 and older will quadruple}

U.S. population ages 65 and older, 2010-2050

\begin{tabular}{|c|c|c|c|c|}
\hline$\square$ Age 90+ & & & 79.7 million & 83.7 million \\
\hline$\square$ Age 80-89 & & 72.8 million & 5.6 & 8.0 \\
\hline घAge 70-79 & & 3.3 & & \\
\hline Age 65-69 & $\begin{array}{c}56.0 \text { million } \\
2.8\end{array}$ & 16.1 & 22.1 & 22.9 \\
\hline 40.3 million & 10.4 & & & \\
\hline 9.4 & 24.8 & 33.2 & 34.0 & 32.7 \\
\hline 16.6 & & & & \\
\hline 12.4 & 18.1 & 20.1 & 18.1 & 20.1 \\
\hline 2010 & 2020 & 2030 & 2040 & 2050 \\
\hline
\end{tabular}

Figure 2 In the United States, the older adult population is expected to reach 83.7 million Americans by 2050. The number of older adults greater than 80 years will comprise 36.9 percent. With permission, Kaiser Family Foundation (2). https://www.kingsfund.org.uk/copyright.

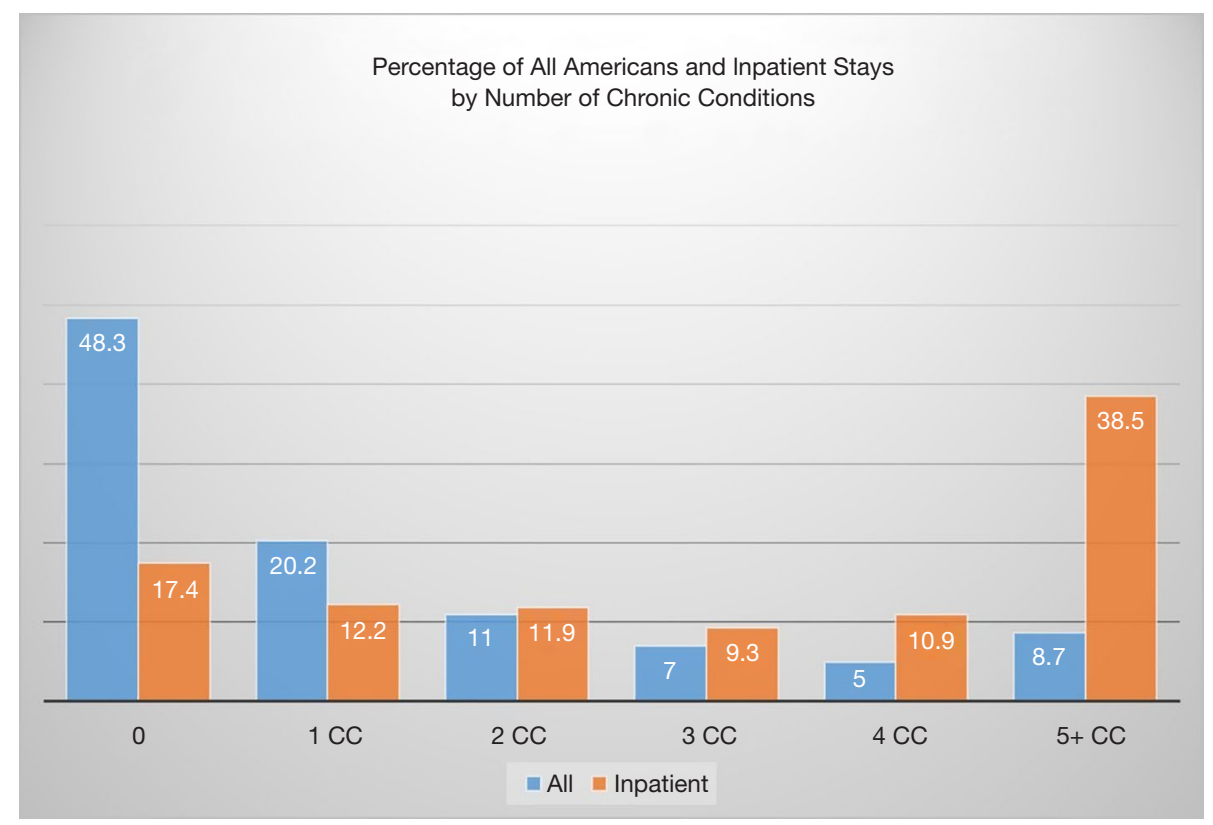

Figure 3 Agency for Healthcare Research and Quality (AHRQ) funded 2010 Medical Expenditure Panel Survey. Among all American inpatients, the number of individuals with multiple chronic condition (MCC) comprise 70.6 percent of the total. Dramatically, 38.5\% of these admitted patients have five or more MCCs. With permission, adapted from (5). https://www.ahrq.gov/sites/default/files/wysiwyg/ professionals/prevention-chronic-care/decision/mcc/mccchartbook.pdf. 


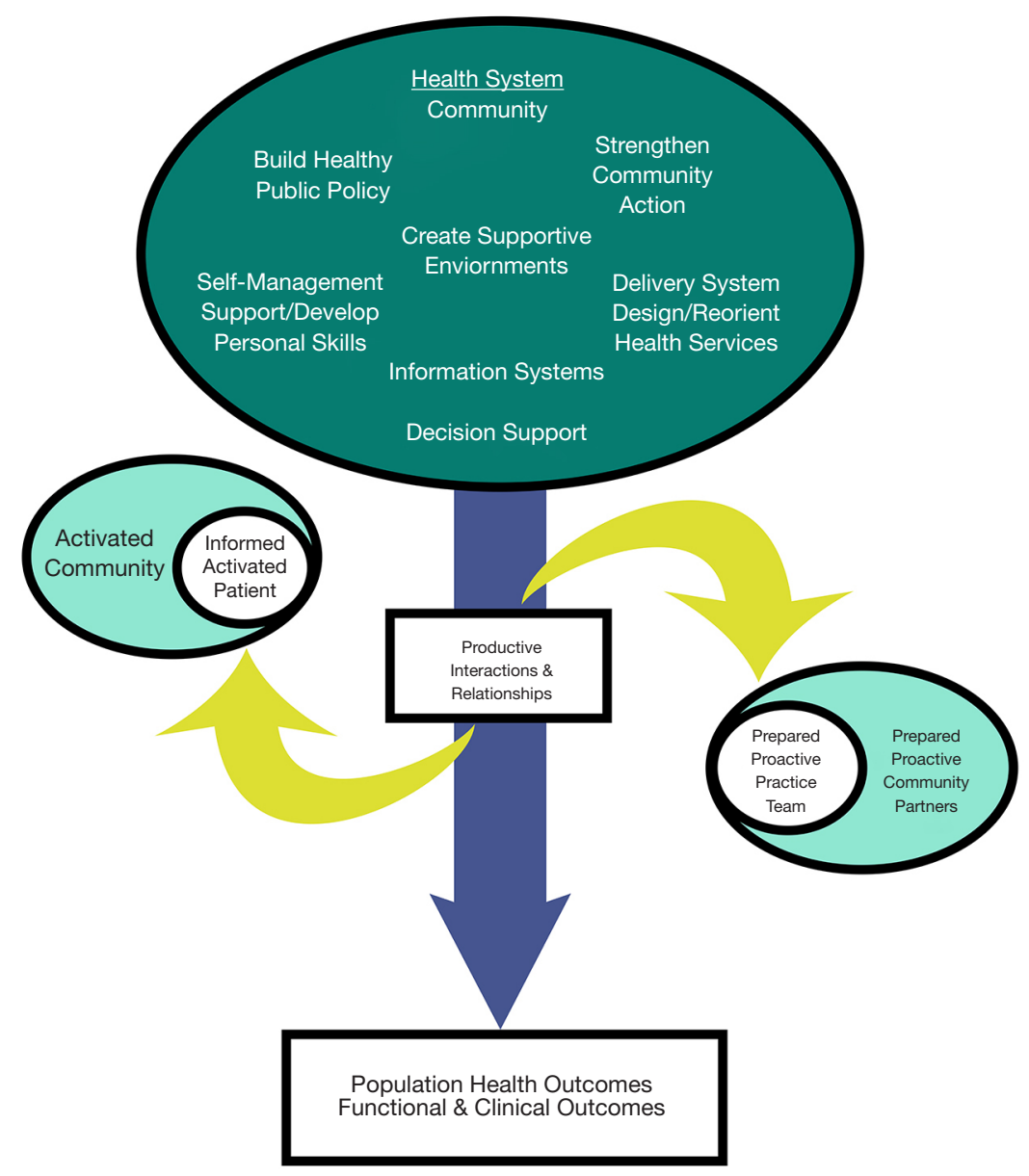

Rendering by Katelyn Newman

Figure 4 This review illustrates the use of the value-based chronic care model (CCM) for establishing an activated community in the "assisted" self-management capability with an activated and informed older adult. With permission, adapted from (16). https://www.longwoods.com/ publications/healthcare-quarterly.

susceptibility to ill health and which hampers the recovery process to normal health once ill health has occurred (12)." We describe the vulnerable/frail older adult as representing a spectrum of complex care needs. It is well known that a chronological definition is too simplistic and at times is viewed from a one-size fits-all framework (13). The chronic care model (CCM), introduced over two decades ago, improves health outcomes of patients by changing to a person-centered care delivery approach (14). The CCM comprises six distinct concepts identified as modifiable of health care delivery. In this review, we will address the spectrum of capability of the older population in self-management abilities (SMA). We view value-based CCM of older adults further through coordinated individual and community-focused care team partners termed assisted self-management (15). From a pragmatic standpoint, interventions are identified from the uninformed/inactivated spectrum to one of an "informed/ activated" patient, caregiver, and community-integrated care team (Figure 4) (16-18). This review takes a populationbased approach for caring for people with MCCs. In addition, we discuss the use of the Model for Improvement (MFI) and the role of patient and community measurement.

\section{The role of health literacy as a social determinant of health assessment tool among the vulnerable older population}

Understanding the older population requires the integrated 
nature of physiology, psychology, as well as social and cultural heterogeneity $(19,20)$. Within this framework, we believe it is crucial to identify vulnerable/frail individuals (21). The description of vulnerability as a dynamic state, as mentioned above, is best defined as the interactions and accumulation of deficits inhibiting older adult's ability to safely perform daily functions impacting their quality of life (21). Even though vulnerable seniors may suffer from mental illness, cognitive deficits, or functional impairment, if possible, they should participate in the process of decision making. A study of vulnerability/ frailty was modified from a 36 self-reported health assessment variables obtained at baseline and subsequently at 2-year interval to determine deficit accumulation (22). A dose response association between age group and prevalence of vulnerability was seen beginning at age 75 years of age. The level of support to keep these individuals functional is sometimes all that is necessary. An informal home visit by a community health worker or service may reveal deficits that an older adult has been concealing. The goals of intervention are to maintain autonomy and ensure safety. Capable adults who refuse intervention should be offered information regarding services that are available (22).

Health risk assessment (HRA) Plus utilizes principles and techniques that can be tailored to meet the needs of older adults (23). HRA Plus carefully assesses one's risk of negative health outcomes, readiness to change certain behaviors, confidence in doing so, and the relative pros and cons for initiating behavior change (23). Evidence-based HRAs provide feedback to patients and their support system that allows them to more accurately assess the likelihood of future problems. Research has shown that self-efficacy is associated with a person's motivation in making lifestyle or behavior changes and his or her ability to manage the disease (23). Quality-adjusted life years (QALYs) take into account one's experience of living given the addition of years to life. HRA Plus can be the initial step in a personalized shared decision-making (SDM) prevention plan framework that supports successful healthy behavior and risk reduction (20). Ongoing health education programs can be provided through one-on-one sessions or pamphlets, books, videos, and interactive computer programs (23).

Providers who offer HRA Plus interventions should employ a person-centered approach in which treatment options take into account the patient's perspective (23). Important care support services, including caregivers and community services, can be provided outside the healthcare system. Through a SDM process, providers and patients can prioritize interventions to improve self-management of existing disease. The SDM process begins with gathering relevant information from the patient and then using that information to prompt productive communication leading to action (23). Second, addressing mutually agreed upon options can reduce the patients' health risks and encouraging building confidence. It is important to consider areas that the patient deems critically important, as well as high-priority risk (23). Operationally, SDM is achieved through communication, self-formulated and realistic goal setting, self-monitoring, the establishment of support systems, and ongoing feedback (23). Patient-provider discussions may uncover barriers to change that include physical pain, emotional difficulties, financial concerns, and lack of confidence in one's ability to change.

Language and cognition issues have a significant impact on the ability to engage in SDM (24). Addressing oral communication and numeracy skills in health literacy has been described as a crisis in Europe and beyond (25). Providers must take action to understand the needs of their patient populations and employ practices that help address those needs. Many U.S. adults lack the literacy skills needed to use health-related print materials and tools consistently (26). The National Assessment of Adult Literacy (NAAL) focused on written materials as "the ability of US adults to use printed and written health-related information to function in society to achieve one's goals, and to develop one's knowledge and potential $(27,28)$." The NAAL revealed $36 \%$ of the adults had basic or below basic health literacy skills (Table 1). Adults 65 and older had the lowest health literacy scores. Those with the lowest literacy/health literacy were 65 years or older, male, and Black or Hispanic; spoke another language prior to formal education; have less than a high school diploma; live at or below the poverty line; rate their overall health as poor; and do not seek health information $(27,28)$. In another study, $71 \%$ of older adults have difficulty in using print materials (20). Sixtyeight percent had difficulty with quantitative tasks. Older adults with access to resources and more than a high school education had stronger literacy skills than those adults living in poverty at any education level (29). Recommendations for health professionals include adjusting expectations and demands including the literacy environment designed for older adults $(30,31)$.

Health literacy has been defined in numerous ways over time and is still evolving (31). An expansive definition included in the WHO's Health Promotion Glossary $(32,33)$. Health literacy implies a level of knowledge and ability 
Table 1 Health Literacy scores (range, 0-500) reflecting the abilities needed at a particular level. Thirty-six percent of individuals were identified with basic or less health literacy level. With permission NCES, adapted from (27)

\begin{tabular}{ll}
\hline Health literacy & Description \\
\hline Below basic [0-184] & No more than the most simple and concrete skills \\
& This level is well below that needed to function within the healthcare setting \\
& Skills necessary to perform simple and everyday activities \\
Basic [185-225] & $\begin{array}{l}\text { Individuals at this level are able to read, understand, and use information in short, simple, and } \\
\text { everyday level }\end{array}$ \\
Intermediate [226-309] & $\begin{array}{l}\text { Skills necessary to perform moderately challenging activities } \\
\text { Individuals in this category are able to read and understand moderately difficult text and noting the } \\
\text { purpose of less common written material } \\
\text { Proficient [310-500] }\end{array}$ \\
& Skills necessary to perform more complex and challenging literacy activities \\
\hline
\end{tabular}

https://nces.ed.gov/.

to understand and use information towards improving an individual's or community's health (30-32). As health literacy researchers became more attentive to the barriers involved in the use of words, jargon phrases, numbers, and numeric concepts, some focused their attention on the skills of health professionals $(30,31)$. Age-related changes have an association with health literacy and health management performance. Individuals with limited health literacy experience multiple unintended negative consequences consisting of more medication errors, more inpatient and Emergency Department (ED) care, and inability to use e-health worsens health status (29). A better understanding of which processes contribute to limited health literacy in older adults that contribute to declining health literacy as people age is needed $(30,31)$.

Clinicians may have trouble identifying patients with limited health literacy. Health Literacy Universal Precautions are aimed at simplifying communication and confirming comprehension for all patients (20). Rudd et al. [2012] highlight that health literacy is considered a social determinant of health (30). While research indicates that limited literacy skills may result in untoward outcomes, a mismatch between the demands of health information and care systems may be equally impactful. The health literacy toolkit provides evidence-based guidance to support practitioners in addressing health literacy (34). It describes the domains of health literacy focusing on spoken/ written communication, self-management and supportive systems (34). Efforts at increasing health equity and reducing health disparities will eliminate health literacy barriers (35-37).

Health literacy is a powerful contributor to the social determinants of health $(\mathrm{SDoH})$. The rate of low health literacy in the U.S. is significantly linked to race, ethnicity, income, education level, and age (30). Further health literacy research suggest that interventions are associated with improvements in clinical outcomes and health care utilization $(30,31)$. These interventions offer health care systems, providers, and those working in the community to identify new approaches in addressing disparities beyond conditional screening, treatment, or care delivery.

\section{Value-based CCM}

In tailoring initiatives to an individuals' needs it is well established that communication is essential to improving quality care and patient safety. Value-based care coordination models offer a methodological framework for coordinating patient-centered services and ensuring efficient access to the health care system and needed supports (Figure 4) (38). Care coordination addresses the complexity of health care systems and offers an enhanced approach to care delivery for older adults. All of these models use some form of case identification and intervention to attempt to produce better care (38).

The first step is to identify high-cost populations that offer the greatest opportunity for cost containment who could benefit most from care coordination services (38). A care coordinator identifies health goals and coordinates services to meet those goals. This function may be 
Table 2 Patient activation measure (PAM) is derived from a 13-item scale (score 0-100 units). The activation level or "vital sign" allows for progress checks and tailoring support interventions towards the individual or community. With permission, adapted from (53)

\begin{tabular}{|c|c|c|c|}
\hline $\begin{array}{l}\text { PAM } \\
\text { level }\end{array}$ & Range of engagement assessment & $\begin{array}{l}\text { PAM } \\
\text { score }\end{array}$ & Interventions \\
\hline 1 & $\begin{array}{l}\text { Passive and overwhelmed to starting } \\
\text { to take a role in managing own health }\end{array}$ & $\leq 47.0$ & $\begin{array}{l}\text { Build knowledge base, self-awareness, \& initial confidence negotiating an action } \\
\text { plan that focuses on self-awareness, role delineation, and stress management }\end{array}$ \\
\hline 2 & $\begin{array}{l}\text { Lack of knowledge and confidence } \\
\text { to building knowledge \& confidence }\end{array}$ & $\begin{array}{l}\geq 47.1 \\
\leq 55.1\end{array}$ & $\begin{array}{l}\text { Increase in knowledge, initial skills development, and growing confidence. } \\
\text { Building a sense of self-efficacy }\end{array}$ \\
\hline 4 & $\begin{array}{l}\text { Maintaining behaviors but may } \\
\text { decline due to life stressors }\end{array}$ & $\geq 72.5$ & $\begin{array}{l}\text { Achieve/exceed lifestyle, behavior guidelines, and develop techniques to } \\
\text { prevent relapse. Acquiring coping and problem-solving skills that undermine the } \\
\text { maintenance of behaviors }\end{array}$ \\
\hline
\end{tabular}

performed by a nurse manager, social worker, community health worker, or layperson. At its essence, the care coordinator is the person responsible for ensuring that the care plan is carried out in partnership with the person at the center of the plan. The care teams, at their best, are either based in the community or at least respond to the specific circumstances of the individual and family working at the center of the care plan (16,39).

The value-based CCM is an integral part of the patientcentered medical home models (40-42). One example of improved care within a group of patients actively participating in the heart failure collaborative had fewer ED visits and fewer hospital days (43). Value-based CCM emphasizes self-management and care support with the integration of all members of the care team $(44,45)$. Evaluation of the program has shown some effectiveness in stimulating improved self-management and reductions in costs (46). While patient activation is a central concept in the CCM, it is also the least well-developed element (47). Patient and community activation have a key role in influencing health care quality and costs (47). Even though patient activation is a central concept in both the consumerdriven health care approach and value-based CCM, it remains conceptually and empirically underdeveloped (44,48-50).

\section{Patient activation measure (PAM) scale}

PAM was developed to assess an individual's knowledge, skill, and confidence for self-management (51-53). It is a survey consisting of thirteen items based on strong psychometric properties categorized into one of four levels where higher scores indicate a more activated patient in managing their own health (Table 2). The activation level allows for progress checks and tailoring support towards the individual or community. (54,55). Tailoring interventions based on the activation level improves the care processes for people at that level. For example, PAM level can be determined from an individual's response to taking medications as directed. Only about $33 \%$ of those in the PAM level 1 lowest activation level indicate that they read about possible side effects or complications when prescribed a new medication (56). Only $25 \%$ bring a list of questions to the medical encounter for discussion.

Older adults often have lower health literacy and often find it difficult to take an active role in healthcare decisionmaking $(57,58)$. Health literacy was significantly lower for participants over 80 years of age, women, lower education status, lower monthly income, living alone, chronic illness, and poor mental health status. Those who have low levels of activation are less likely to actively participate in their health status (53). Tailoring service delivery according to patient activation levels can maximize productivity and efficiency by ensuring that the level of support provided is appropriate to the needs of the individual. There is an association between health literacy and SMA of adults aged 75 and older (45). Low health literacy was associated with poor SMA in a wide range of older adults. Early recognition of low health literacy among adults of 75 and older and interventions to improve health literacy might be very beneficial.

In an U.S. sample of mostly female patients, the level of activation was found to predict remission or improvement of moderate to severe depression at 12 months (59). Baseline patient activation is significantly lower in older 

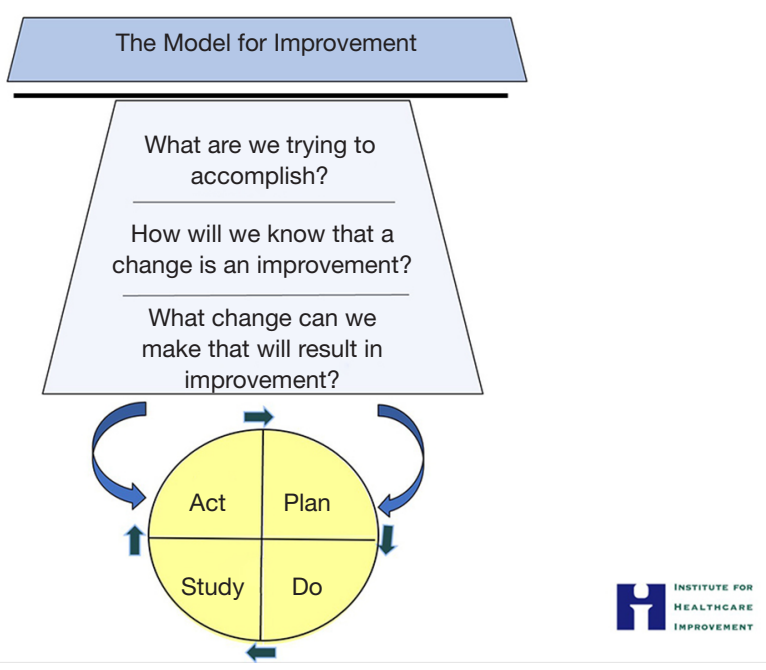

Figure 5 The Model for Improvement (MFI) is recognized as an important tool for quality interventions. MFI begins by asking three fundamental questions. The initial focus of MFI is creating a valid and measurable Aim Statement. The Plan-Do-StudyAct (PDSA) process allows for evaluating iterative steps. With permission (63). Source: IHI.org.

patients, those with depression, and those with poor health literacy (60). Depression has the strongest association with patient activation. Depressed patients who are better activated were also more likely to engage in health behaviors. Those who self-reported 2 or more long-term morbidities including depression, impaired health literacy, lack of social support, and greater impact of multimorbidity were all significantly associated with worse patient activation scores at baseline (57).

The PAM instrument is useful for designing an intervention and evaluating increased activation at the community level (61). In supportive social environments of home, family, and neighborhoods, participants had higher older adult activation. Community-level efforts create multiple supportive social environment opportunities that could increase activation (61). One advantage of community-level strategies is that different organizations can reinforce similar messages and widespread support. For example, key community-based groups working together to promote the idea of an active role in supporting an individual's health would likely have a greater impact. A focus on activation as an outcome of care could be transformative moving away from a provider-centric to a patient-centered perspective supporting efforts aimed towards the patient. Studies to date demonstrate that even when older patients have multiple chronic illnesses, they can still gain in activation and control over their daily lives $(60,62)$. Patients achieving self-care and self-management activation had better health outcomes and were able to collaborate with providers; and navigate the health care system $(56,62)$. The limited self-management skills of older adults may result in a higher than expected need of caregiver assistance (60).

\section{Using the MFI to improve patient activation}

In many communities, a disparity exists between the needs of the chronically ill and the care delivery system which was largely designed for acute illness. Assessing an individual patient's internal and external risk for adverse outcome can lead to a change in treatment, increased interaction with the patient and planning for supportive resources. Affecting positive change in a community or cohort of patients requires a more structured plan. Applying the principles of improvement science is a positive step in improving care of the chronically ill. As the Institute for Healthcare Improvement (IHI) describes:

The science of improvement is an applied science that emphasizes innovation, rapid-cycle testing in the field, and spreading innovations to foster learning about what actions produce improvements. It is characterized by the combination of expert subject knowledge with improvement methods and tools. It is multidisciplinary-drawing on clinical science, systems theory, psychology, statistics, and other fields (IHI.org).

The science of improvement is activated using the MFI (63) (Figure 5). Why use the MFI? Because it provides an organizing structure to guide thinking, ensure discipline, and thoughtfulness. Developed by Associates in Process Improvement the MFI is a simple yet powerful tool that fosters a common language in the pursuit of improvement (64). The MFI three questions: what are we trying to accomplish? How will we know that a change is an improvement? What changes can we make that will result in improvement? The second step employs Plan-Do-StudyAct (PDSA) cycles for small, rapid-cycle tests of change (63).

Applying the MFI in the care for the chronically ill will require some pre-work and focus. What are the known issues in this community? Are there external factors (transportation, availability of medical care, etc.) or internal factors (health literacy, confidence) that need to be studied and resolved? How would you know?

An improvement team might employ a cause and effect 


\section{Cause and Effect}

Issues leading to poor outcomes of care in the older patient with multiple chronic conditions

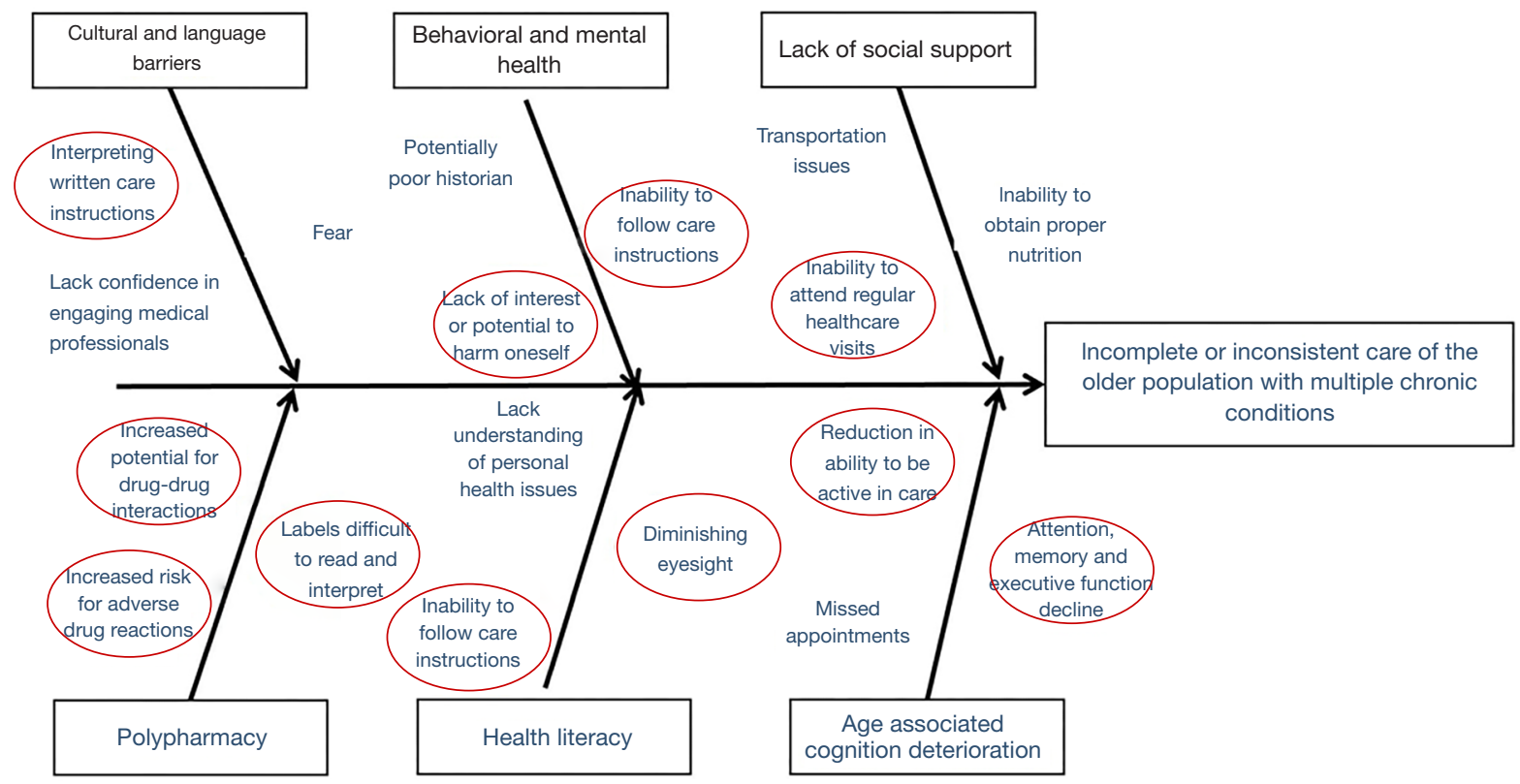

Figure 6 The process an improvement team might employ to better understand factors that lead to poor or adverse outcomes in the MCC population. The main causative factors for the potential of medication mismanagement are circled in red. MCC, multiple chronic condition..

process to better understand factors that lead to adverse outcomes in the MCC population. The IHI QI Essentials Toolkit provides several valuable templates to manage quality projects (65). For example, the Ishikawa cause and effect diagram (also known by Fishbone diagram), credited to its inventor Kaoru Ishikawa, demonstrates a breakdown of the causes of adverse outcomes of care in this population. After brainstorming this qualitative data, the improvement team would further analyze the causes and decide on priorities for improvement study. As an example, the team may use an adaption of the traditional Ishikawa diagram to identify many causative factors of medication mismanagement in the MCC group (Figure 6).

The process commences with the establishment of an improvement project team and trending undesirable outcomes. For instance, investigating a high percentage of missed appointments could reveal transportation issues or a lack of understanding of the importance of follow-up visits. An unexpected number of post-operative infections could uncover deficiencies in health literacy and patients' understanding of self-care. Examining ED visits might expose unsuccessful medication management, which could indicate a health literacy concern.

Here we offer an example of the MFI to assess a specific patient cohort's health literacy. The success of medication management will be evaluated.

What are we trying to accomplish? Improvement requires setting aims and requires that a specific study population be defined. The aim should be time-specific and measurable.

Within 12 months, reduce medication mismanagement related ED visits to less than $15 \%$ of all $\mathrm{ABC}$ Practice patients having 2 or more documented chronic conditions.

How will we know that a change is an improvement? The next step is to establish measures. Measures should provide information to calculate whether changes lead to an improvement. For example, how many ED visits related to medication mismanagement were made by members of this study cohort in the last 12 months? If a change is made, will the number of visits related to medication mismanagement be reduced?

What changes can we make that will result in 


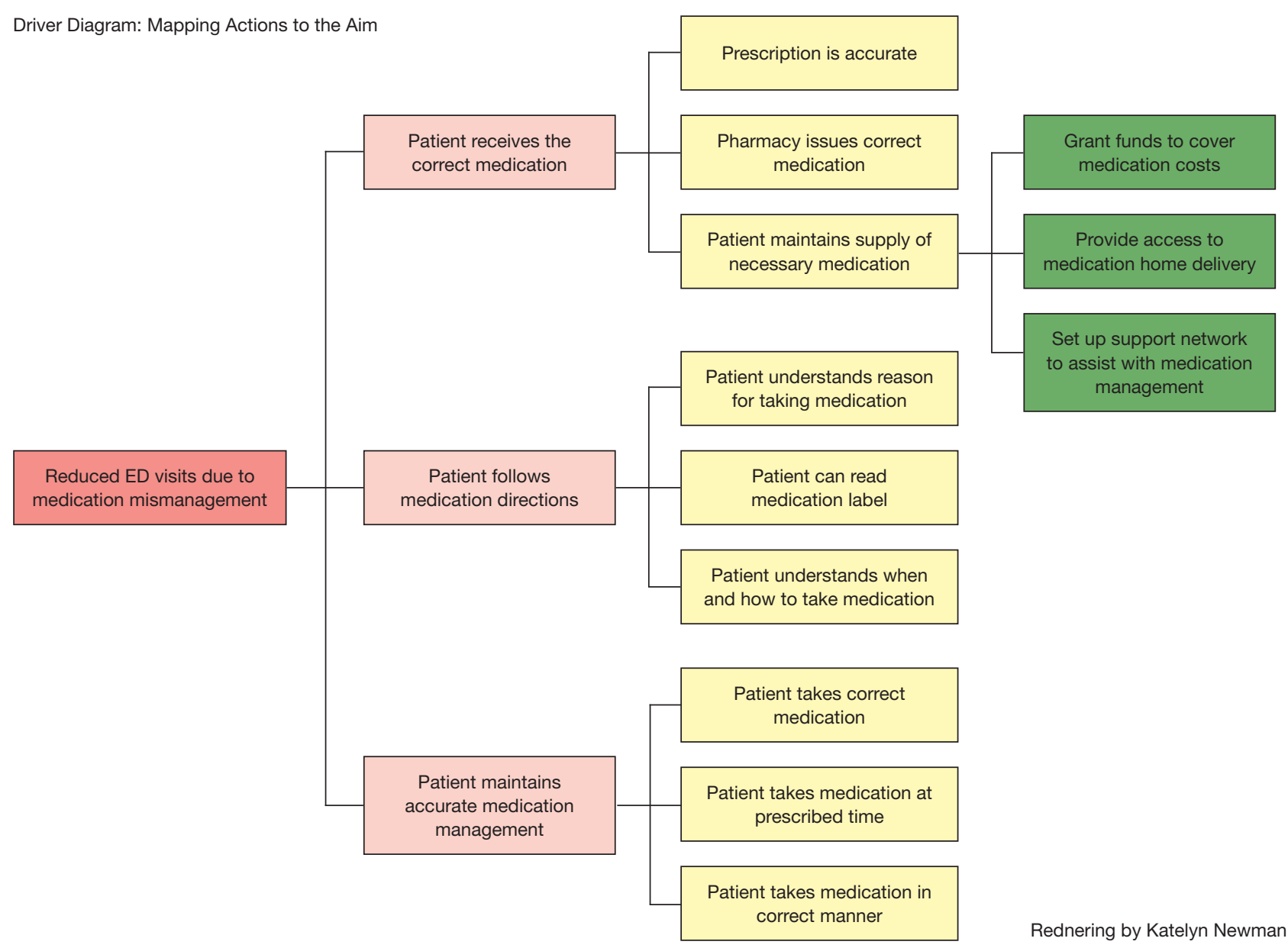

Figure 7 The driver diagram prioritizes key areas to establish a prioritized improvement plan. ED, emergency department.

improvement? Improvement occurs only when a change is implemented, but not all changes result in improvement. Testing a change or conducting a limited, controlled pilot study is an effective way to determine if an initial improvement plan will result in a positive change. A Driver Diagram provides a roadmap from the desired outcome (aim) to the actions that will lead to that improvement (Figure 7). Now that the team has established the prioritized improvement actions, the plan is trialed and monitored.

Encouraging results should be analyzed against balancing measures; did this improvement cause an unexpected burden? An example: improved medication self-management also resulted in increased staff time resulting in salary cost increases during the pilot. Balancing information is vital to know before full scale implemented commences. Once the three questions have been answered and the test or pilot is complete, the PDSA cycle is employed. The PDSA cycle is the application of the science for improvement; an adaptation of the scientific method to test changes in the real-life setting (IHI.org). Plan: all patients in the study cohort (all patients in the ABC Practice with two or more documented chronic conditions) will receive weekly phone calls to discuss medication management. Calls will commence on an identified date and continue for 12 months. Do: each team member will receive a list of patients to call each week. A standardized questionnaire will be followed and documented during each call. The survey is designed to stimulate conversation and evaluate the patient's understanding of the prescribed medication regimen. Missed or unanswered phone calls will be logged. After collecting data on ED visits, the team will analyze those data to determine visits that resulted from medication mismanagement. Study: complete the analysis. Have the results improved over the initial baseline? Was 


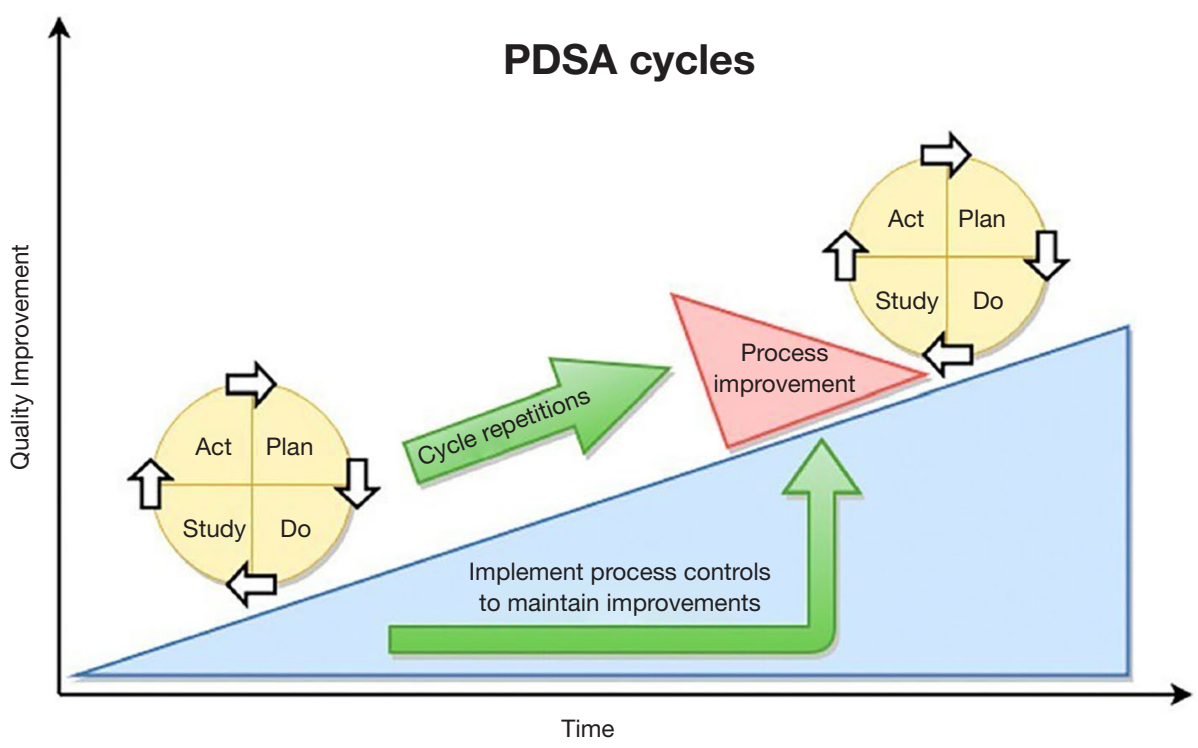

Figure 8 The Plan-Do-Study-Act (PDSA) cycle is an iterative continuous process until the aim is achieved and sustained. With permission, Wolters Kluwer (66).

the aim achieved? Act: if results are showing a positive trend, continue as planned. If the data does not show improvement, the improvement team should discuss results and make corrective actions to the plan. The PDSA cycle continues until the aim is achieved and sustained (Figure 8) (66).

There are measurable benefits to using a structured model for improving care; many benefits extend beyond the individual improvement project. The MFI provides an organizing structure to guide analysis and action and ensures that that scientific discipline is applied to improvement programs. Improvement teams develop a common language and standardize processes, leading to a reduction in variations in practice. With each implementation of the MFI, organizations gain greater clarity into processes and interactions that drive the system of care for their patients.

\section{Future perspectives involving tailored care management}

Current trends in health care innovation for the aging patient with MCCs have recognized that a more effective approach requires health services to be tailored to the needs and resources redirected and tailored to the individual's environment. Health, "the ability to adapt and to selfmanage", is a challenge for vulnerable and frail older adults (67). Social isolation, defined as a lack of social contacts and engagement, is a social determinant of health among senior adults affecting their ability of selfmanagement. Aoki et al. (2018) report that social isolation is associated with negative outcomes of all-cause mortality hospital readmissions, falls, cognitive decline, and suicide (68). Improving social connectedness through a "tailored" integrated health care model most effectively addresses the SDoH barriers involving older adults.

Value-based CCM intervention integrates changes involving most or all of the six elements: community, health care system, self-management support, delivery system design, decision support, and clinical information systems $(16,39,42)$. These reported studies suggest that redesigning care using the value-based CCM leads to improved patient care and better health outcomes. The primary aim of integrated care or chronic disease management programs is to reduce fragmentation while at the same time improving health outcomes at an acceptable cost to the healthcare system (48). Current trends in health care delivery and management have included care coordination and community health networks to dramatically improve health care (17). An innovative and integrated model has been describe incorporating best practices and projects into a health care system that can effectively address the multidimensional health care challenges related to the aging patient with MCCs. We believe that a community-centered "Tailored" Integrated Healthcare Management System addresses our proposal for an interactive and informed 
patient, caregivers, and community care team. It allows for more autonomy and quality of life for older vulnerable adults while improving cost-efficiency, promoting a culture of public participation and interagency collaboration. This benefits older patients with MCCs including complex and multidimensional problems. The multidimensionality of MCC of the senior population is associated with significant health costs associated with different aggravation factors appearing together with a general deterioration of physical and cognitive abilities $(4,8,54)$.

It is important to remember that in order for any care model to be effective it must be flexible to the needs and resources for the patient. Initially, practitioners identify the patient's needs and resources. It is generally easy to identify medical needs, but further investigation should be performed to identify the patient's overall vulnerability, and their potential activation level. As discussed above, the patient's socioeconomic, cultural, physical, cognitive, and geographic characteristics along with their health literacy will define the patient's needs.

Once their needs are identified, the provider and patient should work together to determine what resources are available to the patient. Maintaining an actively updated database and understanding of resources for the most costly and disruptive chronic conditions will allow the healthcare team to focus on the most vulnerable patients. Community resources can include care by a home care nursing program, social worker, nurse navigator, or even a lay person with specific understanding or training regarding the patient's needs.

In a tailored delivery model, the challenges that have been identified along with the support that is available defines what the patient will be able manage on an individual level. Since all of the above challenges and resources vary, the delivery model must be flexible. As the team increases the patient's activation the patient can take on more of their own care. For the vulnerable population, patient involvement may be a smaller proportion of their overall care with the increased reliance on community, healthcare, and provider support.

\section{Conclusions}

Growing aging populations with MCC are at risk for poorer health outcomes from less adequate overall care. A transformation away from clinical guidelines and disease management programs to the totality of the needs of the population is essential as we grapple with escalating health costs $(68,69)$. Poor health literacy affects older adult's ability to optimize SMA. Value-based CCM interventions directed at improving decision-making and healthrelated quality of life will have a positive impact on care delivery and controlling cost (57). A modified "Tailored" Integrated Health Care Model comprising the following components of health care e-governance, patient-centered, home- and community-based management models, selfmanagement models, and palliative care address the areas of an informed/activated individual with the "assistance level" by an activated community. Improved integrative community and patient/caregiver activation for vulnerable/ frail older population with poor health literacy, inadequate SMA, and low PAM scores utilizing the CCM and the MFI methodologies to tailor effective interventions. The PAM will allow for all stakeholders to determine the progress of an older adult patient and determine which interventions are required.

\section{Acknowledgments}

The authors wish to recognize the valuable input of Drs. Mitchell Kaminski and Joel Reich as a sounding board for some of the concepts presented in this review. The learners' contributions from the Thomas Jefferson University College of Population Health for their thoughtful discussions and critiques of the thoughts generated in the preparation of this study were appreciated. We would like to thank our illustrator, Katelyn Newman, who provided the graphic designs.

Funding: None.

\section{Footnote}

Provenance and Peer Review: This article was commissioned by the editorial office, Fournal of Gastrointestinal Oncology for the series "Global GI Malignancies". The article has undergone external peer review.

Conflicts of Interest: All authors have completed the ICMJE uniform disclosure form (available at http:// dx.doi.org/10.21037/jgo-20-317). The series "Global GI Malignancies" was commissioned by the editorial office without any funding or sponsorship. JFG and QDC served as the unpaid Guest Editors of the series. JFG serves as an unpaid editorial board member of Fournal of Gastrointestinal Oncology from Jan 2019 to Dec 2020. EG reports that she is Assistant Program Director of Healthcare Quality and 
Safety and Adjunct Professor of Population Health at Jefferson College of Population Health, Thomas Jefferson University, 901 Walnut Street, 10th floor, Philadelphia, PA 19107, 215.955.3888. The authors have no other conflicts of interest to declare.

Ethical Statement: The authors are accountable for all aspects of the work in ensuring that questions related to the accuracy or integrity of any part of the work are appropriately investigated and resolved.

Open Access Statement: This is an Open Access article distributed in accordance with the Creative Commons Attribution-NonCommercial-NoDerivs 4.0 International License (CC BY-NC-ND 4.0), which permits the noncommercial replication and distribution of the article with the strict proviso that no changes or edits are made and the original work is properly cited (including links to both the formal publication through the relevant DOI and the license). See: https://creativecommons.org/licenses/by-nc-nd/4.0/.

\section{References}

1. Pew Research Center. January 2014. "Attitudes about Aging: A Global Perspective. Available online: https:// www.pewresearch.org/global/2014/01/30/attitudes-aboutaging-a-global-perspective/

2. Neuman T, Cubanski J, Huang J, et al. The Rising Cost of Living Longer: Analysis of Medicare Spending by Age for Beneficiaries in Traditional Medicare. 2015. Available online: https://www.kff.org/medicare/report/the-risingcost-of-living-longer-analysis-of-medicare-spending-byage-for-beneficiaries-in-traditional-medicare/

3. Chang S, Goldstein NE, Dharmarajan KV. Managing an Older Adult with Cancer: Considerations for Radiation Oncologists. Biomed Res Int 2017;2017:1695101.

4. Hajat C, Stein E, Yach D. Multiple Chronic Conditions: The Global State. 2017. Available online: https://www. tevapharm.com/globalassets/tevapharm-vision-files/teva mcc_report.pdf

5. Gerteis J, Izrael D, Deitz D, et al. Multiple Chronic Conditions Chartbook. AHRQ Publications No, Q14-0038. Rockville, MD: Agency for Healthcare Research and Quality, April 2014. Available online: https://www.ahrq.gov/

6. WHO Global Action Plan for the Prevention and Control of Noncommunicable Diseases. 2013-2020. World Health Organization. Available online: https://www.who.int/

7. Ackland M, Choi BC, Puska P. Rethinking the terms non- communicable disease and chronic disease. J Epidemiol Community Health 2003;57:838-9.

8. Hajat C, Stein E. The global burden of multiple chronic conditions: A narrative review. Prev Med Rep 2018;12:284-93.

9. Gleason KM, McDaniel MR, Feinglass J, et al. Results of the Medications at Transitions and Clinical Handoffs (MATCH) Study: An analysis of medication reconciliation errors and risk factors at hospital admission. J Gen Intern Med 2010;25:441-7.

10. Claxton AJ, Cramer J, Pierse C. A systematic review of the association between dose regimens and medication compliance. Clin Ther 2001;23:1296-310.

11. Osterberg L, Blaschke T. Adherence to medication. $\mathrm{N}$ Engl J Med 2005;353:487-97.

12. de Groot N, Bonsel GJ, Birnie E, et al. Towards a universal concept of vulnerability: Broadening the evidence from the elderly to perinatal health using a Delphi approach. PLoS One 2019;14:e0212633.

13. Surbone A, Kagawa-Singer M, Terret C, et al. The illness trajectory of elderly cancer patients across cultures: SIOG position paper. Ann Oncol 2007;18:633-8.

14. Vestjens L, Cramm JM, Birnie E, et al. Evaluating an integrated primary care approach to improve well-being among frail community-living older people: A theoryguided study protocol. BMC Geriatr 2018;18:173.

15. Wagner EH, Austin BT, Von Korff M. Organizing care for patients with chronic illness. Milbank Q 1996;74:511-44.

16. Barr VJ, Robinson S, Martin-Link B, et al. The expanded Chronic Care Model: an integration of concepts and strategies from population health promotion and the Chronic Care Model. Hosp Q 2003;7:73-82.

17. Gandarillas MÁ, Goswami N. Merging current health care trends: innovative perspective in aging care. Clin Interv Aging 2018;13;2083-95.

18. Wagner EH. Chronic disease management: what will it take to improve care for chronic illness? Eff Clin Pract 1998;1:2-4.

19. Culo S. Risk assessment and intervention for vulnerable older value. Both internal factors, such as cognitive impairment, and external factors, such as inadequate housing, can threaten the health and safety of older adults. B C Med J 2011;53:421-5.

20. Brega AG, Barnard J, Mabachi NM, et al. AHRQ Health Literacy Universal Precautions Toolkit. 2nd edition. Prepared by Colorado Health Outcomes Program, University of Colorado Anschutz Medical Campus under Contract No. HHSA290200710008, TO\#10. AHRQ 
Publication No. 15-0023-EF. Rockville, MD: Agency for Healthcare Research and Quality, January 2015.

21. Long P, Abrams M, Milstein A, et al. editors. Effective Care for High-Need Patients: Opportunities for Improving Outcomes, Value, and Health. Washington, DC: National Academy of Medicine, 2017.

22. Song X, Mitnitski A, Rockwood K. Prevalence and 10-year Outcomes of Frailty in Older Adults in Relation to Deficit Accumulation. J Am Geriatr Soc 2010;58:681-7.

23. Goetzel RZ, Staley P, Ogden L, et al. A framework for patient-centered health risk assessments: providing health promotion and disease prevention services to Medicare beneficiaries. Atlanta, GA: US Department of Health and Human Services, Center for Disease Control and Prevention, 2011.

24. Wilson-Stronks A, Lee KK, Cordero CL, et al. One Size Does Not Fit All: Meeting the Health Care Needs of Diverse Populations. Oakbrook Terrace, IL: The Joint Commission, 2008.

25. Kickbusch I, Pelikan JM, Apfel F, et al. Health literacy: The solid facts. Copenhagen: World Health Organization Regional Office for Europe, 2013.

26. Chesser AK, Keene Woods N, Smothers K, et al. Health Literacy and Older Adults: A Systematic Review. Gerontol Geriatr Med 2016;2:2333721416630492.

27. Kutner M, Greenberg E, Jin Y, et al. The Health Literacy of Americas Adults: Results from the 2003 National Assessment of Adult Literacy (NCEC 2006-483). U.S. Department of Education. Washington, DC: National Center for Education Statistics, 2006.

28. Cutilli CC, Bennett IM. Understanding the health literacy of America: results of the National Assessment of Adult Literacy. Orthop Nurs 2009;28:27-32; quiz 33-4.

29. Centers of Disease Control and Prevention. Improving Health Literacy for Older Adults: Expert Panel Report 2009. Atlanta: U.S. Department of Health and Human Services, 2009.

30. Rudd RE, McCray AT, Nutbeam D. Health Literacy and Definition of Terms. In: Begoray DL, Gillis D, Rowlands G. editors. Health Literacy in Context: International Perspectives. Nova Science Publishers, 2012:13-32.

31. Rudd RE. Health Literacy: Insights and Issues. In: Logan RA, Siegel ER. editors. Health Literacy. IOS Press, 2017. doi: 10.3233/978-1-61499-790-0-60.

32. Nutbeam D. The evolving concept of health literacy. Soc Sci Med 2008;67:2072-8.

33. Smith BJ, Tang KC, Nutbeam D. WHO Health Promotion: new terms. Health Promot Int 2006;21:340-5.
34. DeWalt DA, Callahan LF, Hawk VH, et al. Health Literacy Universal Precautions Toolkit. (Prepared by North Carolina Network Consortium, the Cecil G. Sheps Center for Health Services Research, The University of North Carolina at Chapel Hill, under Contract No. HHSA290200710014.) AHRQ Publication No. 10-0046EF. Rockville, MD: Agency for Healthcare and Quality, April 2010.

35. Logan RA, Wong WF, Villaire M, et al. Health Literacy: A Necessary Element for Achieving Health Equity. Washington, DC: Discussion Paper, Institute of Medicine, 2015.

36. Roundtable on Health Literacy; Board on Population Health and Public Health Practice; Institute of Medicine. Health Literacy: Improving Health, Health systems, and Health Policy around the World: Workshop Summary. Washington (DC): National Academies Press (US), 2013 Jul 10.

37. Rudd RE. The evolving concept of Health Literacy: New directions for health literacy studies. J Commun Health 2015;8:7-9.

38. Craig C, Eby D, Whittington J. Care Coordination Model: Better Care at Lower Cost for People with Multiple Health and Social Needs. IHI Innovation Series white paper. Cambridge, Massachusetts: Institute for Healthcare Improvement, 2011.

39. Wagner EH, Davis C, Schaefer J, et al. A Survey of leading chronic disease management programs: are they consistent with the literature. J Nurs Care Qual 2002;16:67-80.

40. Stiefel M, Nolan K. A guide to Measuring the Triple Aim: Population, Experience of Care, and Per Capita Cost. IHI Innovation Series white paper. Cambridge, Massachusetts: Institute for Healthcare Improvement, 2012.

41. CMS Care Coordination Toolkit. 2019. Available online: https://www.hsag.com/care-coord-tools

42. Coleman K, Austin BT, Brach C, et al. Evidence on the Chronic Care Model in the New Millennium: Thus far, the evidence on the Chronic Care Model is encouraging, but we need better tools to help practices improve their systems. Health Aff (Millwood) 2009;28:75-85.

43. Byrnes J, Carrington M, Chan YK, et al. Cost-effectiveness of a Home Based Intervention for Secondary Prevention of Readmission with Chronic Heart Disease. PloS One 2015;10:e0144545.

44. Wagner EH, Austin BT, Davis C, et al. Improving chronic illness care: translating evidence into action. Health Aff (Millwood) 2001;20:64-78.

45. Geboers B, de Winter AF, Spoorenberg SLW, et al. The 
association between health literacy and self-management abilities in adults aged 75 and older, and its moderators. Qual Life Res 2016;25:2869-77.

46. Lorig K. Chronic disease self-management program: insights from the eye of the storm. Front Public Health 2015;2:253. Erratum in: Front Public Health. 2015;3:153.

47. Greene J, Hibbard J, Tusler M. How much do health literacy and patient activation contribute to older adults' ability to manage their health? Washington, DC: AARP, 2015.

48. Davy C, Bleasel J, Liu H, et al. Effectiveness of Chronic Care Models: Opportunities for improving healthcare practice and health outcomes: a systematic review. BMC Health Serv Res 2015;15:194.

49. Mills WR, Poltavski D, Douglas M, et al. A Platform and Clinical Model to Enable Medicare's Chronic Care Management Program. Popul Health Manag 2020;23:107-14.

50. Glasgow RE, Orleans CT, Wagner EH. Does the chronic care model serve also as a template for improving prevention? Milbank Q 2001;79:579-612, iv-v.

51. Hibbard JH, Stockard J, Mahoney ER, et al. Development of the Patient Activation Measure (PAM): conceptualizing and measuring activation in patients and consumers. Health Serv Res 2004;39:1005-26.

52. Hibbard JH. Using systematic measurement to target consumer activation strategies. Med Care Res Rev 2009;66:9S-27S.

53. Hibbard J, Gilbury H. Supporting people to manage their health: An introduction to patient activation. The King's Fund, 2014.

54. Hibbard JH, Greene J. What the Evidence Shows About Patient Activation: Better Health Outcomes and Care Experiences; Fewer Data on Costs. Health Aff (Millwood) 2013;32;207-14.

55. Hibbard JH, Greene J, Overton V. Patients with lower activation associated with higher costs; delivery systems should know their patients' scores. Health Aff (Millwood) 2013;32:216-222.

56. Mosen DM, Schmittdiel J, Hibbard J, et al. Is Patient Activation Associated with Outcomes of Care for Adults

Cite this article as: Gibbs JF, Guarnieri E, Chu QD, Murdoch K, Asif A. Value-based chronic care model approach for vulnerable older patients with multiple chronic conditions. J Gastrointest Oncol 2021;12(Suppl 2):S324-S338. doi: 10.21037/jgo-20-317 with Chronic Conditions? J Ambul Care Manage 2007;30:21-9.

57. McCaffery KJ, Holmes-Rovner M, Smith SK, et al. Addressing health literacy in patient decision aids. BMC Med Inform Decis Mak 2013;13 Suppl 2:S10.

58. Overbeek A, Rietjens JAC, Jabbarian LJ, et al. Low patient activation levels in frail older adults: a cross-sectional study. BMC Geriatr 2018;18:7.

59. Sacks RM, Greene J, Hibbard J, et al. How well do patient activation scores predict depression outcomes 1 year later? J Affect Disord 2014;169:1-6.

60. Blakemore A, Hann M, Howells K, et al. Patient activation in older people with long-term conditions and multimorbidity: correlates and change in a cohort study in the United Kingdom. BMC Health Serv Res 2016;16:582.

61. Hibbard JH. Community-based Participation Approaches and Individual Health Activation. J Ambul Care Manage 2009;32:275-7.

62. Frosch DL, Rincon D, Ochoa S, et al. Activating seniors to improve chronic disease care: results from a pilot intervention study. J Am Geriatr Soc 2010;58:1496-503.

63. Institute for Healthcare Improvement. Available online: http://www.ihi.org/

64. Associates in Process Improvement. Available online: http://www.apiweb.org/

65. Institute for Healthcare Improvement. QI Essentials Toolkit, 2017. Available online: http://www.ihi.org/ resources/Pages/Tools/Quality-Improvement-EssentialsToolkit.aspx

66. Girdler SJ, Glezos CD, Link TM, et al. The Science of Quality Improvement. JBJS Rev 2016;4:e2.

67. Huber M, Knottnerus JA, Green L, et al. How should we define health? BMJ 2011;343:d4163.

68. Aoki T, Yamamoto Y, Ikenoue T, et al. Social Isolation and Patient in Older Adults. Ann Fam Med 2018;16:393-8.

69. Vogeli C, Shields AE, Lee TA, et al. Multiple chronic conditions: prevalence, health consequences, and implications for quality, care management and costs. J Gen Intern Med 2007;22:391-5. 